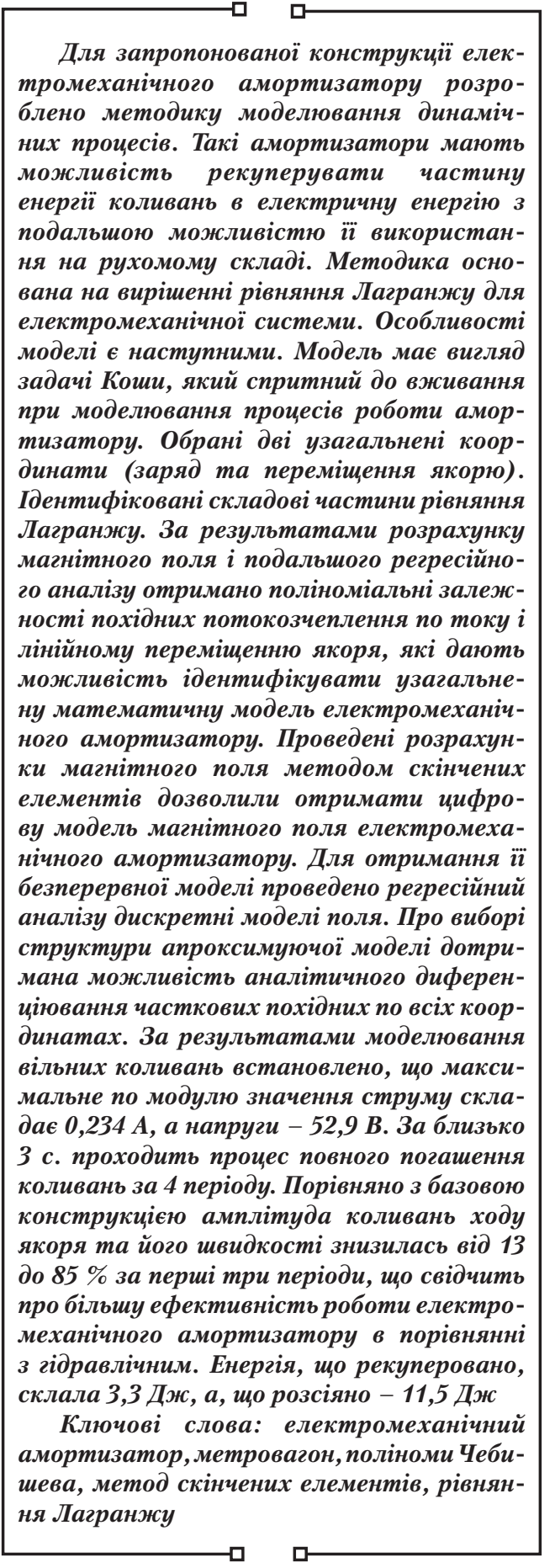

UDC 629.429.3:621.313

DOI: $10.15587 / 1729-4061.2019 .181117$

\section{PROCEDURE FOR MODELING DYNAMIC PROCESSES OF THE ELECTROMECHANICAL SHOCK ABSORBER IN A SUBWAY CAR}

\author{
B. Li u barskyi \\ Doctor of Technical Sciences, Professor \\ Department of Electrical Transport \\ and Construction of Diesel Locomotives** \\ E-mail: Iboris1911@ukr.net \\ N. Luk a s hova \\ Assistant \\ Department of Electrical Transport* \\ E-mail: lukaschova.natalya@gmail.com \\ O. P e tr e n k o
}

Doctor of Technical Sciences, Associate Professor Department of Electrical Transport*

B. Yerits y a n $P h D * *$

E-mail: bagish_ericjan@ukr.net Y. Kovalchuk Postgraduate Student

Department of Finance and the Financial and Economic Security Higher State Educational Institution "Banking University" Peremohy ave., 55, Kharkiv, Ukraine, 61174

E-mail: berezhnaya.yuliia@gmail.com

L. Overianova

$\mathrm{PhD}$, Associate Professor**

E-mail: overanova@ukr.net

*O. M. Beketov National University of Urban Economy in Kharkiv

Marshala Bazhanova str., 17, Kharkiv, Ukraine, 61002

**National Technical University «Kharkiv Polytechnic Institute» Kyrpychova str., 2, Kharkiv, Ukraine, 61002*** $\star * *$ Department of Electrical Transport and Construction of Diesel Locomotives
Received date 10.08.2019 Accepted date 06.10.2019 Published date 28.10.2019
Copyright (C) 2019, B. Liubarskyi, N. Lukashova, O. Petrenko, B. Yeritsyan, Y. Kovalchuk, L. Overianova This is an open access article under the CC BY license (http://creativecommons.org/licenses/by/4.0)

\section{Introduction}

The main element in the subway car running gear is the system of spring suspension. The effective running gear operation requires the presence in its structure of oscillation absorbers - shock absorbers that ensure the car ride smoothness. Shock absorbers reduce external influences exerted on the running gear of electric rolling stock by irregularities in a track and decrease oscillations induced by the running gear, which affect the elements of electric rolling stock and a rail track.

The dynamic parameters of shock absorbers predetermine traffic safety and electric rolling stock speed in the intracity and rail line transportation. The smooth movement and dynamic performance of rolling stock are affected, first of all, by the type and structure of oscillation absorbers. The best indicators in terms of motion smoothness are demonstrated by pneumatic shock absorbers [1]; their use, however, 
requires an additional pneumatic supply system - compressors, which reduce the overall energy efficiency of electric rolling stock.

An alternative approach to improving the dynamic indicators of the running gear of electric rolling stock is the use of electromechanical shock absorbers [2]. These shock absorbers make it possible to recuperate part of the energy of oscillations into electrical energy providing for the subsequent possibility of using it by rolling stock.

International experience of constructing and using electromechanical shock absorbers gives grounds for prospects of their application for the running gear of subway cars. Employing electromechanical converters as shock absorber contributes to the improved efficiency of electric rolling stock operation in general, owing to the possibility to control the force of damping. In this case, there is the possibility to recuperate electrical energy into the network; in contrast to using other types of shock absorbers [2].

\section{Literature review and problem statement}

At present, for the most common subway cars in Ukraine, the series Ezh, their modifications and 81-717, 81-714, spring suspension oftrolleysconsists of thejournaland centralones [3]. The latter is used to transmit the traction force from the carriage of a car body, the loading from the body weight, to the trolley frame, as well as rebalances the body relative to trolleys, thereby softening the shocks and impacts arising from the irregularities of the track and when fitting the curved sections at rolling stock motion. To reduce the friction forces, which are harmful to the over-spring structures in the transmission of hard impacts, the central suspension, as well as in the journal suspension of trolleys, tow-row cylindrical springs are used. As regards the design, as well as the technology of manufacturing and repair, they are much simpler than sheet elliptical springs. The suspension that is made using cylindrical springs is more than 1.5 times lighter than the equivalent one, in terms of static deflection of spring suspension, with elliptical springs. Hydraulic shock absorbers are used to damp oscillations that occur at rolling stock motion in the central suspension of trolleys.

Based on the analysis, performed in paper [4], of systems for oscillation damping used by urban rail transport, it was indicated that the most common technical solution is the frictional oscillation dampers, which are mounted in the second degree of a spring suspension. In order to maintain a proper level of motion smoothness, frictional dampers are supplemented with hydraulic dampers. The most advanced designs of subway cars are equipped with suspension that uses pneumatic springs. The shock absorbers, considered above, make it possible to damp oscillations that are created at urban electric transport motion; however, adjusting their parameters at different loading of cars is impossible. The use of pneumatic springs enables adjusting the parameters for damping, depending on the loading of a car and the magnitude of external influences, however, the pneumatic suspension requires additional energy cost and capacities of the pneumatic system [2].
The cars of series E-KM [5], built by upgrading carss Ezh at PJSC "Kryukivsky carriage-building Works" (Kremenchuk, Ukraine), are equipped with new trolleys, model 687054 , with central pneumatic spring suspension supplemented with hydraulic shock absorbers.

Analysis of various types of electromechanical shock absorbers used by vehicles was carried out in paper [2]. It was noted that when choosing the type of an electromechanical transducer for the shock absorber, among the currently known types - asynchronous, synchronous, electromagnetic, and direct current - the best option is the latter $[6,7]$. First two types need, to ensure relatively small displacements, complex semiconductor converters. These converters should change the voltage and frequency to units of Herz at the output. In addition, these types of engines have low re-handling ability. A third one is characterized by a rather uneven characteristic of the traction force due to displacement, which is close to hyperbolic. The electromechanical shock absorber needs a constant traction [8] (mechanical) characteristic that changes only by the speed of the armature movement.

Work [9] estimated the efficiency of using an electromechanical shock absorber with a direct action in combination with a spring using an example of the McPherson type car suspension. The electromechanical shock absorber consists of s multi-pole electric generator of synchronous type excited by permanent magnets. It is noted that this type of a shock absorber, in addition to oscillations damping, can recuperate electrical energy. The processes of energy recovery and its preservation in the onboard energy storage were addressed in paper [10]. The electromechanical shock absorbers can become an additional source of energy for such systems, which could improve energy efficiency of rolling stock in general.

Study [2] proposed a structure of the electromechanical shock absorber for a subway car, shown in Fig. 1.

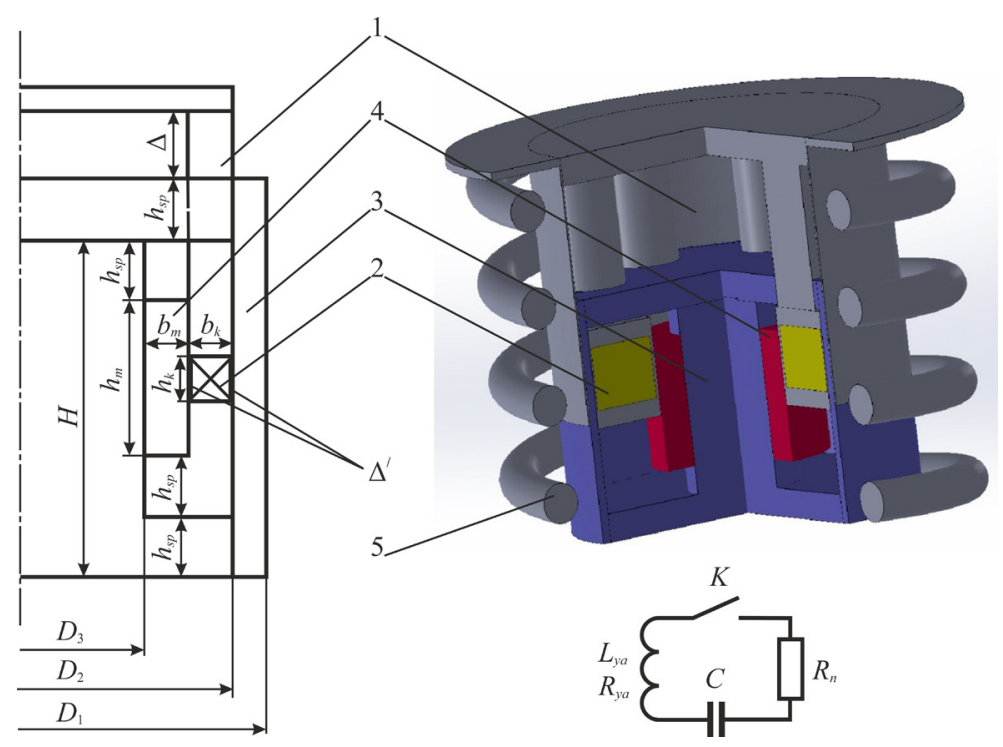

Fig. 1. DC electromechanical shock absorber: 1 - armature; 2 - armature winding; 3 - frame; 4 - permanent magnet; 5 - spring

It was determined that the basic geometric and electromagnetic indicators of the shock absorber correspond to those given in Table 1.

However, the static characteristics of the shock absorber do not make it possible to determine its dynamic qualities 
that predetermine its capability to operate in the systems of spring suspension. To determine the dynamic indicators of the shock absorber, it is necessary to build its mathematical model as an electromechanical system.

Table 1

Basic characteristics of electromechanical shock absorber in accordance with Fig. 1 [2]

\begin{tabular}{|c|c|l|}
\hline Parameter & Magnitude & \multicolumn{1}{|c|}{ Notes } \\
\hline$F_{\text {dem }}$ & $2,000 \mathrm{~N}$ & $\begin{array}{l}\text { Rated electromagnetic force on the } \\
\text { shock absorber armature }\end{array}$ \\
\hline$V_{\text {dem }}$ & $0.08 \mathrm{~m} / \mathrm{s}$ & $\begin{array}{l}\text { Rated velocity of the shock absorber } \\
\text { armature }\end{array}$ \\
\hline$\Delta$ & $0.08 \mathrm{~m}$ & Shock absorber maximal stroke \\
\hline$H_{c}$ & $9.5105 \mathrm{~A} / \mathrm{m}$ & $\begin{array}{l}\text { Coercive force of a permanent } \\
\text { magnet }\end{array}$ \\
\hline$B_{\text {ost }}$ & $1.05 \mathrm{Tl}$ & $\begin{array}{l}\text { Ultimate permanent magnet induc- } \\
\text { tion }\end{array}$ \\
\hline$H_{\max }$ & $0.3 \mathrm{~m}$ & $\begin{array}{l}\text { Maximum height of the shock } \\
\text { absorber yoke }\end{array}$ \\
\hline$h_{s p}$ & $0.035 \mathrm{~m}$ & Height of the yoke back \\
\hline$b_{k}$ & $0.093 \mathrm{~m}$ & Coil width \\
\hline$h_{k}$ & $0.081 \mathrm{~m}$ & Coil height \\
\hline$D_{1}$ & $0.429 \mathrm{~m}$ & Shock absorber outer diameter \\
\hline$D_{2}$ & $0.407 \mathrm{~m}$ & Yoke inner diameter \\
\hline$D_{3}$ & $0.138 \mathrm{~m}$ & Magnet inner diameter \\
\hline$h_{m}$ & $0.161 \mathrm{~m}$ & Magnet width \\
\hline$b_{m}$ & $0.04 \mathrm{~m}$ & Magnet height \\
\hline$W$ & 3,348 & Number of turns \\
\hline$H$ & $0.299 \mathrm{~m}$ & Shock absorber yoke height \\
\hline$I$ & $2.227 \mathrm{~A}$ & $\begin{array}{l}\text { Rated current of the shock absorber } \\
\text { winding }\end{array}$ \\
\hline$E$ & $898 \mathrm{~V}$ & Rated EMF of the shock absorber \\
\hline
\end{tabular}

Modeling is based on equations of the generalized electromechanical transducer of energy (Crohn's machine) [11].

When constructing such models, assumptions are made about the linearity of the magnetic system, the uniformity (smoothness) of an air gap. These assumptions make it possible to construct systems with relatively weak nonlinearities. It is impossible to account for local saturations occurring in linear electromechanical systems, to which an electromechanical shock absorber in a frame belongs, under such an approach. Therefore, the models, widely used at present, that are created based on this principle yield significant errors. However, their main advantage is a capability to implement software-oriented models that make it possible to perform calculations of dynamic processes rather quickly; given the modern level of technology, even close to real time. That makes it possible to use them as a basis for algorithms that control microprocessor systems of automated drives of different types [12].

Another approach is the construction of a "circuit-field" model of the electromechanical transducer [13]. Under this approach, the electromechanical shock absorber parameters are determined based on the results from calculating a magnetic field [14]. Typically, using numerical methods, such as a finite-element method [15], is proposed for it. The magnetic field parameters, obtained in this way (flux linkage and its derivatives - the differential inductance and a coefficient for counteracting electromotive force (CEMF) [12, 15]), identify the mathematical model. These models are significantly better at describing the processes in an electromechanic transducer; however, the computational cost increases considerably. The order of these models can be assessed in the form of a system that employs tens, hundreds of thousands of nonlinear algebraic equations, which in turn identify the differential equations constituting the mathematical model of the transducer.

Therefore, it appears expedient to devise an approach that would make it possible to build a mathematical model of the electromechanical shock absorber, whose order would be much lower than the order of the model proposed in [14]. The feature of such a model could be accounting for local saturations and nonlinearity of the electromechanical converter. As it follows from our analysis of the current state of this issue, that could solve part of the problem associated with the derivation of dynamic indicators such as the time and efficiency of oscillation damping, as well as a possibility to construct a generalized mathematical model of the spring suspension in a subway car.

\section{The aim and objectives of the study}

The aim of this study is to devise a procedure for modeling dynamic processes in the electromechanical shock absorber in a subway car. This would make it possible to determine dynamic indicators of the electromechanical shock absorber.

To accomplish the aim, the following tasks have been set:

- to define the main provisions for a mathematical model of the electromechanical shock absorber;

- to identify parameters for a mathematical model of the electromechanical shock absorber in a subway car;

- to model and analyze the shock absorber operation at free oscillations in order to confirm the adequacy and feasibility of the model.

\section{Modelling dynamic processes of the electromechanic shock absorber in a subway car}

We accepted the following assumptions in our study. The accumulated electromagnetic energy, which is used to describe the machine, is regarded only as a field energy of zero order, that is the energy of a static magnetic field.

The electrostatic field energy is concentrated only in the capacitor.

\section{1. Basic provisions for the procedure}

We shall select the following generalized energy parameters of the shock absorber: generalized coordinate $q_{k}$, generalized speed $q_{k}^{\prime}$, generalized force pulse $p_{k}$, generalized force $f_{k}$. For a mechanical system, there is generally no doubt what the coordinate, speed, force, or pulse denote. Another situation arises when choosing electrical coordinates [16].

The saved electrical energy of an electromechanical system consists of potential energy and kinetic co-energy. This means that if one denotes the charge $q$ as the generalized coordinate $\mathrm{qk}$, the electric saved energy would be defined as potential.

Let us represent a shock absorber in the form of a system having one electric $q_{1}=q$ and one mechanical coordinate $q_{2}=x$ (Fig. 2). To increase the performance rate of a shock absorber, the electrical circuit includes a capacitor $C$. The electric circuit L-R-C, formed in this way, represents a resonance circuit, which is set to the frequency of natural oscillations of the body of a subway car. 


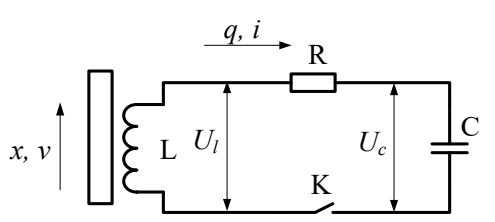

Fig. 2. Electromechanic circuit of shock absorber

If we consider the action of the non-conservative force $Q_{k}$ along the $k$-th coordinate $q_{k}$ together with the conservative forces of the system, then, according to D'Alembert's principle, at dynamic equilibrium, the sum of all forces, including the non-conservative one, should equal zero. Therefore, the Lagrange equation takes the form [16]

$$
\frac{\partial L}{\partial q_{k}}-\frac{\mathrm{d}}{\mathrm{d} t}\left(\frac{\partial L}{\partial \dot{q}_{k}}\right)-\left(\frac{\partial F}{\partial \dot{q}_{k}}\right)+Q_{k}=0,
$$

where $L$ is the Lagrange power function, $F$ is the Rayleigh function that described losses in the system.

After determining the generalized coordinates, we choose a Lagrange power function or the Lagrangian $L(q, \dot{q}, t)$, which will be used to derive equations of motion. A Lagrangian is defined as the difference between the kinetic co-energy $T$ and potential energy $V$, that is

$$
L=T-V .
$$

We shall use generalized variables to write expressions for the kinetic co-energy and potential energy for the conservative part of the system in line with the equations that follow.

Record expressions for the kinetic co-energy and potential energy for the conservative part of the system based on equations (3) and (4) for the electromechanical shock absorber:

$$
\begin{aligned}
& T=\frac{1}{2} \cdot M v^{2}+\int_{0}^{i} \Psi(i, x) \mathrm{d} i, \\
& V=-\frac{1}{2} k\left(x+x_{n}\right)^{2}-\frac{1}{2} C q^{2},
\end{aligned}
$$

where $M, v$ are the oscillating mass and the armature speed equal to $\dot{x} ; \Psi$ is the flux linkage of the coil, $C, q$ is the capacity and charge of the capacitor; $k\left(x+x_{n}\right)$ is the spring resistance force, which is simultaneously included with the shock absorber at rigidity $k$ that is compressed from the beginning by $x_{n}$ meters.

The conservative Lagrangian, in line with (2), equals

$$
L=\frac{1}{2} \cdot M v^{2}+\int_{0}^{i} \Psi(i, x) \mathrm{d} i,-\frac{1}{2} k\left(x+x_{n}\right)^{2}-\frac{1}{2} C q^{2} .
$$

Record a Rayleigh loss function

$$
F=\frac{1}{2}\left(R i^{2}+\alpha v^{2}\right)
$$

where $\alpha$ is the coefficient of mechanical damping, $R$ is total electrical resistance of the shock absorber winding and load.

Substituting expressions (5) and (6) into (1) and by taking appropriate derivatives, we obtain:
- for electrical coordinates, an equation in the form:

$$
\begin{aligned}
& -C q-\frac{\mathrm{d}}{\mathrm{d} t}(\Psi(i, x))-R i=0, \\
& \frac{\int_{0}^{i} \Psi(i, x) \mathrm{d} i}{\partial x}-k\left(x+x_{n}\right)-\frac{\mathrm{d}}{\mathrm{d} t}(M v)-\alpha v+F_{g}=0 .
\end{aligned}
$$

Expression

$$
\frac{\int_{0}^{i} \Psi(i, x) \mathrm{d} i}{\partial x}=F_{e}
$$

determines the electromagnetic force generated by the shock absorber.

Since in the flux linkage $\Psi$ is a complex function that depends on all coordinates, the overall derivative $\frac{\mathrm{d} \Psi}{\mathrm{d} t}$, can be represented in the form

$$
\frac{\mathrm{d} \Psi}{\mathrm{d} t}=\frac{\partial \Psi}{\partial i} \cdot \frac{\mathrm{d} i}{\mathrm{~d} t}+\frac{\partial \Psi}{\partial x} \cdot \frac{\mathrm{d} x}{\mathrm{~d} t} .
$$

Considering $U_{c}=-C q$, record equation (7) in the form

$$
U_{c}-\frac{\partial \Psi}{\partial i} \cdot \frac{\mathrm{d} i}{\mathrm{~d} t}-\frac{\partial \Psi}{\partial x} \cdot \frac{\mathrm{d} x}{\mathrm{~d} t}-R i=0 .
$$

Expressions $L_{d}=\frac{\partial \Psi}{\partial i}$ and $K_{d}=\frac{\partial \Psi}{\partial x}$ determine the differential inductance and a coefficient at CEMF [17], which can be identified based on the results from magnetic field calculations.

In general, expression (7) can be represented in the form:

$$
\left\{\begin{array}{l}
\frac{\mathrm{d} i}{\mathrm{~d} t}=\frac{U_{c}-i \cdot R-K_{d} \cdot v}{L_{d}}, \\
\frac{\mathrm{d} U_{c}}{\mathrm{~d} t}=-\frac{i}{C} .
\end{array}\right.
$$

Given that $F_{g}=M g$, where $g$ is the free fall acceleration, and $\mathrm{M}$ is the reduced body weight, expression (8) can be transformed to the form

$$
\frac{\mathrm{d} v}{\mathrm{~d} t}=\frac{F_{e}-m g-k\left(x+x_{n}\right)-\alpha v}{M} .
$$

By adding to (11) and (12) a relation equation $\frac{\mathrm{d} x}{\mathrm{~d} t}=v$, we obtain a generalized mathematical model of the electromechanical shock absorber in the form of a Cauchy problem.

$$
\left\{\begin{array}{l}
\frac{\mathrm{d} i}{\mathrm{~d} t}=\frac{U_{c}-i \cdot R-K_{d} \cdot v}{L_{d}}, \\
\frac{\mathrm{d} U_{c}}{\mathrm{~d} t}=-\frac{i}{C}, \\
\frac{\mathrm{d} v}{\mathrm{~d} t}=\frac{F_{e}-m g-k\left(x+x_{n}\right)-\alpha v}{M}, \\
\frac{\mathrm{d} x}{\mathrm{~d} t}=v .
\end{array}\right.
$$


Mathematical model (13) takes the form, which is convenient to use when modelling the processes of shock absorber operation; however, its application necessitates the identification of the model parameters - differential inductance and coefficient at CEMF.

4. 2. Identification of parameters of a mathematical model of the electromechanical shock absorber in a subway car

The basic energy parameters of the electromechanical shock absorber are given in Table 1, and its circuit is shown in Fig. 1.

Features of the shock absorber imply, first, that the magnetic field in the working zone is axially symmetrical in nature; second, the dependence of flux linkage in the workflow changes and is not periodic in character.

Similar to [16], the identification of parameters of mathematical model (13) should be carried out using a set of digital experiments representing magnetic field calculation by numerical methods, followed by the subsequent approximation of the results [17]. Fig. 3 shows the estimated area of the magnetic field.

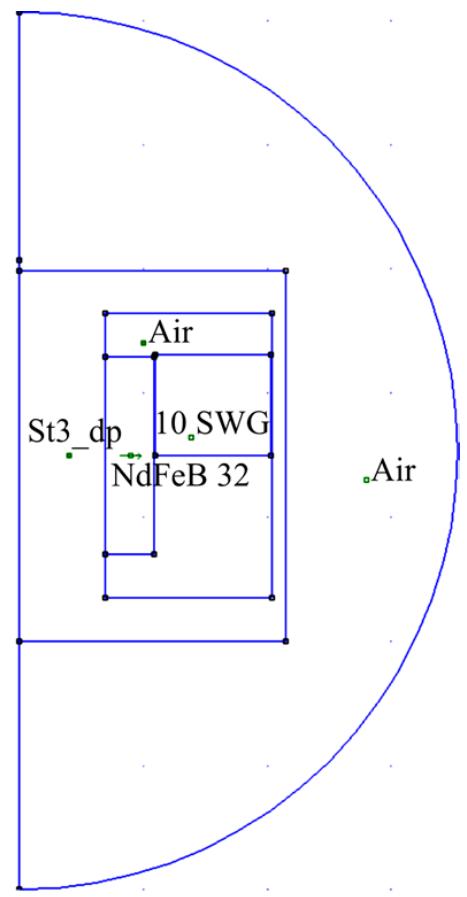

Fig. 3. Estimated area of the magnetic field

The following assumptions were accepted:

- the magnetic field in the region of a linear electromechanical transducer is accepted as axially symmetrical relative to the shock absorber axis;

- the magnetic field is bounded by the spherical region, which is represented in the magnetic field calculation as a semicircle (Fig. 3).

It is proposed using the FEMM software package to calculate the magnetic field [15]. The frame's material is steel St 3, winding - electrotechnical copper; eddy currents and hysteresis are disregarded.

In order to obtain a family of traction characteristics of the engine, a script program was written in the lua language, which automatically changes the $x$ coordinate and the magnetomotive force (MMF) of the winding $-i W$.
In the course of a digital experiment, the armature displacement $x$ varies from 0.1 to $80.1 \mathrm{~mm}$ in increments of $5 \mathrm{~mm}$, and the magnitude of MMF - in the range from $22,368 \mathrm{~A}$ to 22,368 in increments of $2,485.3 \mathrm{~A}$. The variation boundaries are chosen based on the boundary values for these magnitudes in the examined system.

Every step of the calculation was accompanied by the automated calculation of the shock absorber electromagnetic field (Fig. 4); we determined the magnitude of the traction force and flux linkage for the actual values of current and a gap. The magnitude of the force was measured by integration along the contour of the shock absorber armature; the value of flux linkage - based on the cross-section of its winding. The applied approaches are outlined in [15].

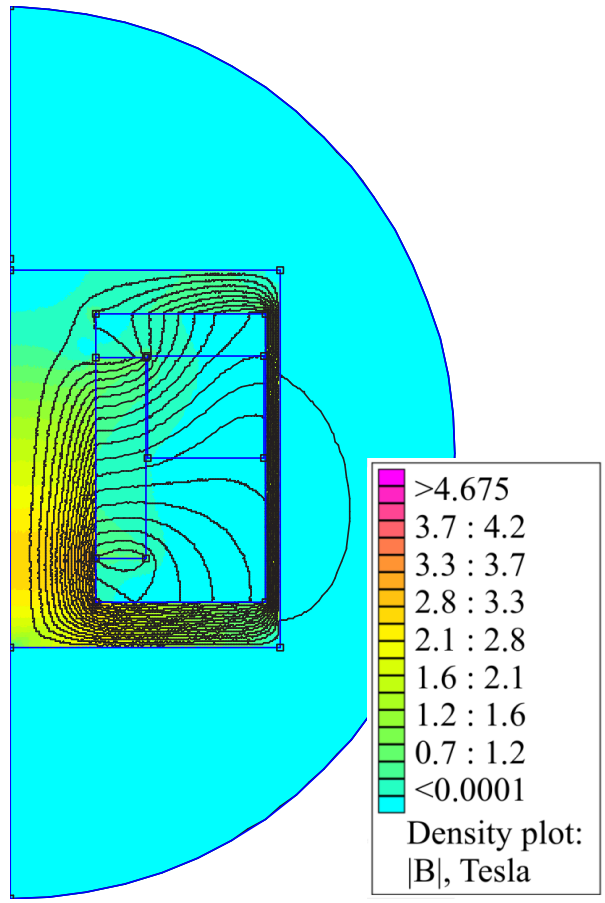

Fig. 4. Results from magnetic field calculation

Our calculations have made it possible to acquire the above digital model of a magnetic field of the electromechanical shock absorber. However, this model is discrete. To obtain a continuous model, a regression analysis of the discrete model must be conducted.

When choosing a structure of the approximating model, it is required that it should have a capability to analytically differentiate partial derivatives along all coordinates. Based on recommendations from [14], approximation of the phase flux linkage takes the form

$$
\Psi(i, x)=\sum_{j=0}^{J} \sum_{k=0}^{K}\left(A L_{j k}(M J \cdot i+Z J)^{j}(M K \cdot x+Z K)^{k}\right),
$$

where $A L_{j k}$ is the coefficient of regression of the polynomial that approximates the flux linkage; $M J, M K$ are the scale coefficients for current and a gap, respectively; $Z J, Z K$ are the offsets for current and a gap, respectively; $J, K$ are the degrees of the approximating polynomial for current and a gap, respectively. 
To determine the coefficients for the approximating polynomial, it is proposed to use a method based on Chebyshev polynomials on the set of equidistant points [14, 17].

By conducting the analytical differentiation for current (14), we obtain differential inductance

$$
\begin{aligned}
& L_{d}=\frac{\partial \Psi(i, x)}{\partial i}= \\
& =\sum_{j=0}^{J} \sum_{k=0}^{K}\left(A L_{j k} j M J(M J \cdot i+Z J)^{j-1} \times\right. \\
& \left.\times(M K \cdot x+Z K)^{k}\right) .
\end{aligned}
$$

After analytical differentiation for the armature stroke (14), we obtain a coefficient at CEMF

$$
\begin{aligned}
& K_{d}=\frac{\partial \Psi(i, x)}{\partial x}= \\
& =\sum_{j=0}^{J} \sum_{k=0}^{K}\left(A L_{j k} k M K(M J \cdot i+Z J)^{j} \times\right. \\
& \left.\times(M K \cdot x+Z K)^{k-1}\right) .
\end{aligned}
$$

The electromagnetic force was approximated with a polynomial, which is of similar type to (14)

$$
\begin{aligned}
& F_{e}=\sum_{j=0}^{J F} \sum_{k=0}^{K F}\left(A F_{j k}(M J F \cdot i+Z J F)^{j} \times\right. \\
& \left.\times(M K F \cdot N+Z K F)^{k}\right),
\end{aligned}
$$

where $A F_{j k}$ is the regression factor of a polynomial that approximates the force; $M J F, M K F$ are the scale coefficients for current and a gap, respectively; ZJF, ZKF are the offsets for current and a gap, respectively; $J F, K F$ are the degrees of the approximating polynomial for current and a gap, respectively.

The permissible maximum deviation $(3.4 \%)$ in the flux linkage approximation is achieved at the minimum values for the degrees of the polynomial $J=4$ and $K=9$, and that for force functions $(2.8 \%)-J F=7$ and $K F=9$.

Dependence graphs of $F_{e}, \Psi, L_{d}$ and $K_{d}$ are shown in Fig. 5-8, respectively.

Thus, the results of magnetic field calculation and the subsequent regression analysis have allowed us to obtain the polynomial dependences of flux linkage derivatives for current and the armature linear displacement, which make it possible to identify the generalized mathematical model of the electromechanical shock absorber.

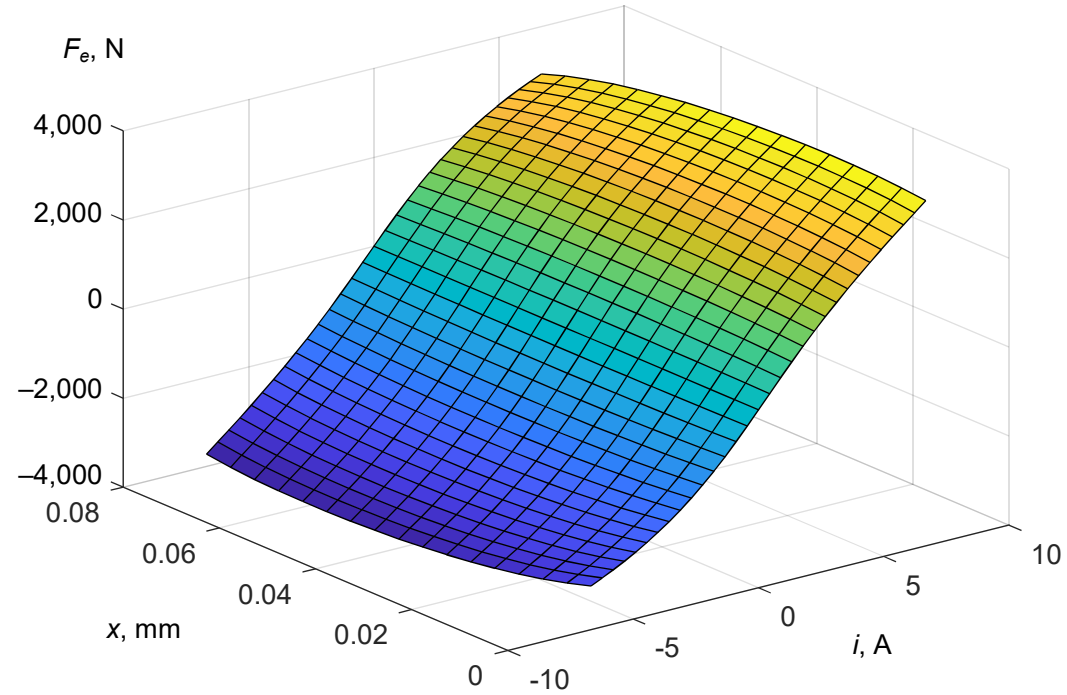

Fig. 5. Dependence of electromagnetic force on the winding displacement and current

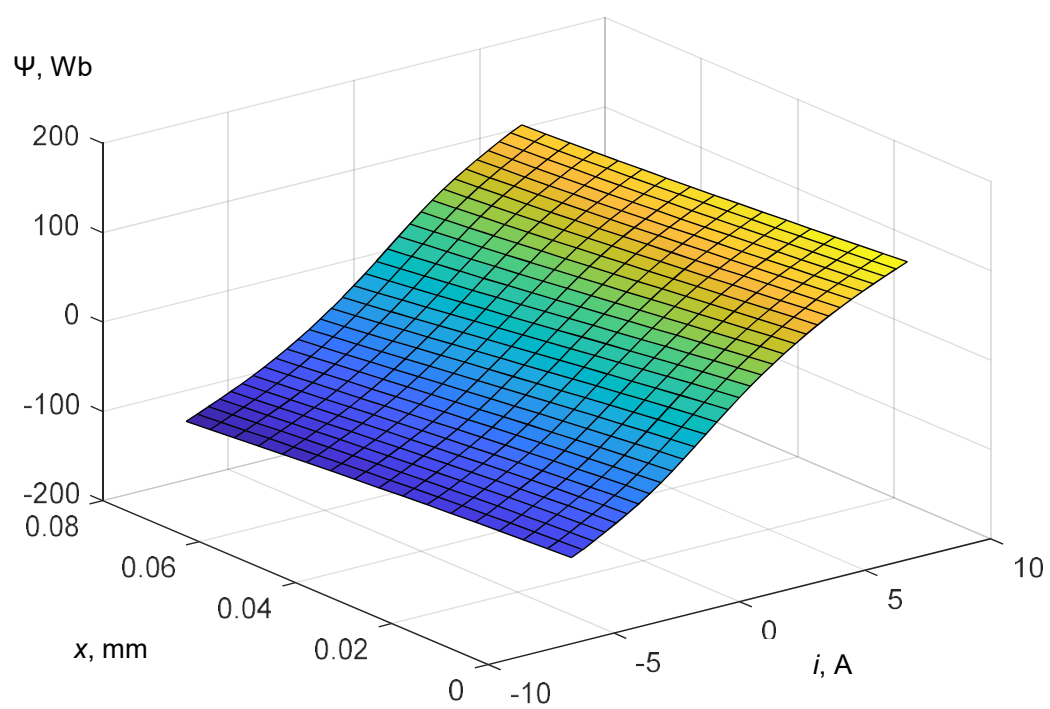

Fig. 6. Dependence of flux linkage in the armature coil on the winding displacement and current

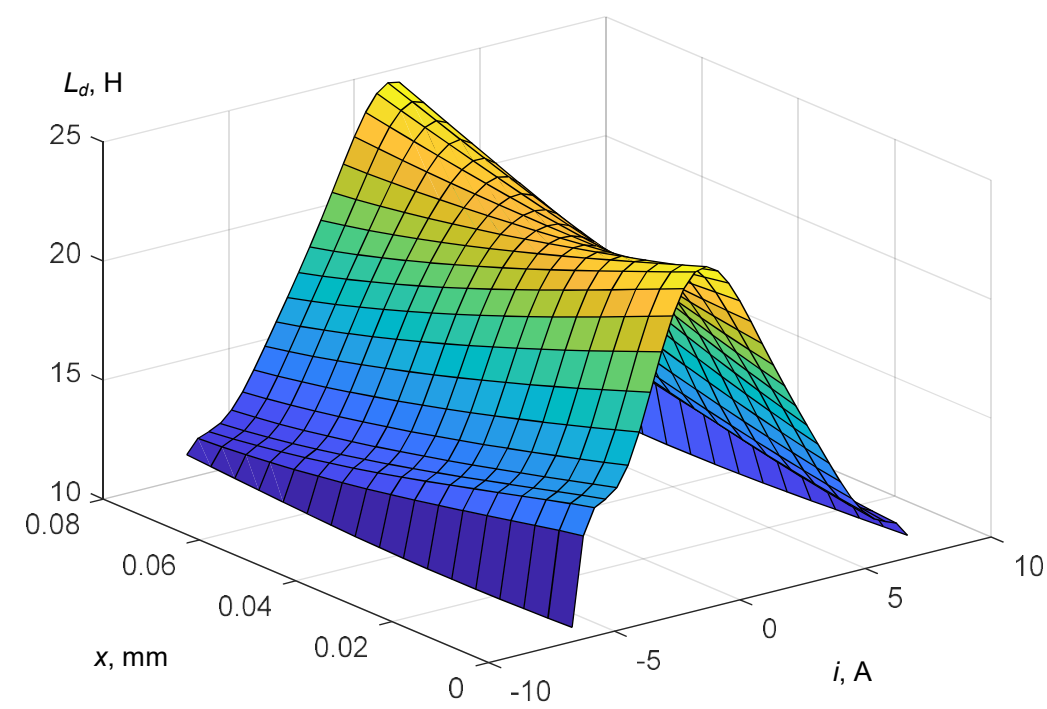

Fig. 7. Dependence of differential inductance on the winding displacement and current 


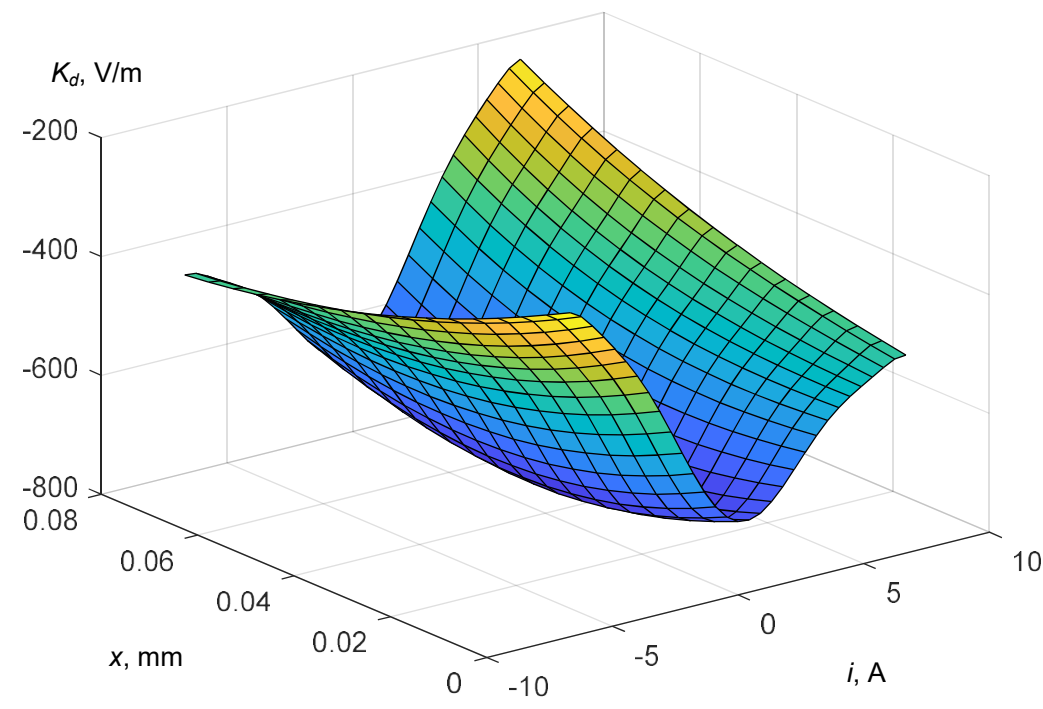

Fig. 8. Dependence of the coefficient at CEMF on the winding displacement and current

\section{Discussion of results from modeling the shock absorber operation using free oscillations as an example}

For the electromechanical system, an electric shock absorber, a mathematical model has been constructed consisting of four differential equations, which accounts for such parameters of the electromechanical transducer as the differential inductance and a coefficient at CEMF and the parameters of the mechanical part, the spring rigidity and the fluctuating mass, as well as the parameters of the system's electric part capacitance system and the total load resistance. The model is represented in the classic form of a Cauchy problem, which makes it possible to solve it by standard numerical methods for solving the systems of differential equations (in the current work, the simulation of free oscillations employed the method of Runge-Kutta of 3-4 order).

When identifying parameters for the electromechanical shock absorber, we determined the degrees of flux linkage polynomials and the force function $(J=4, K=9, J F=7$ and $K F=9$ ), which make it possible, rather adequately, with a maximum deviation of $3.4 \%$ and $2.8 \%$, to reproduce their continuous form. Fig. 5 shows that the electromagnetic force generated by a shock absorber is close to a steady one depending on displacement (the maximum deviation does not exceed $9.2 \%$ of the average value for the force at a constant current in the winding). These changes are due to the increasing fluxes of scattering. The electromagnetic force increases in proportion to the winding current. The coefficient of proportionality decreases due to the increase in the saturation of the magnetic system of an electroshock absorber at greater values of the winding current. The character of change in the flux linkage is close in its nature to the electromagnetic force (Fig. 6). Due to this, the differential inductance (Fig. 7) and the coefficient at CEMF (Fig. 8) demonstrate only a non- linear shape. The differential inductance is maximum at zero value of the winding current, due to the minimum saturation of the magnetic system. The coefficient at CEMF (Fig. 8) is negative over the entire working region, which leads to forming CEMF, which in turn generates the current and electromagnetic force, which counteracts the armature movement direction (provides cushioning).

The represented dependences of electromagnetic force, differential inductance, and the coefficient at CEMF, which identify parameters of the mathematical model, demonstrate only a nonlinear shape. Therefore, their reproduction through a set of digital experiments by using the method of finite elements followed by the regression analysis is justified.

To analyze the results from electromechanical shock absorber operation, the most rational approach is to use an analysis of the system's free oscillations. This is due to the very complex nature of forced oscillations that are predetermined by the running gear of the entire subway car.

$$
\left\{\begin{array}{l}
i(0)=0, \\
u(0)=0, \\
v(0)=0, \\
x(0)=4,5 \cdot 10^{2} .
\end{array}\right.
$$

For a comparative analysis of the results of operation with the basic structure (a hydraulic shock absorber), a comparative modeling of operating modes was carried out. Modeling results are shown in Fig. 9.
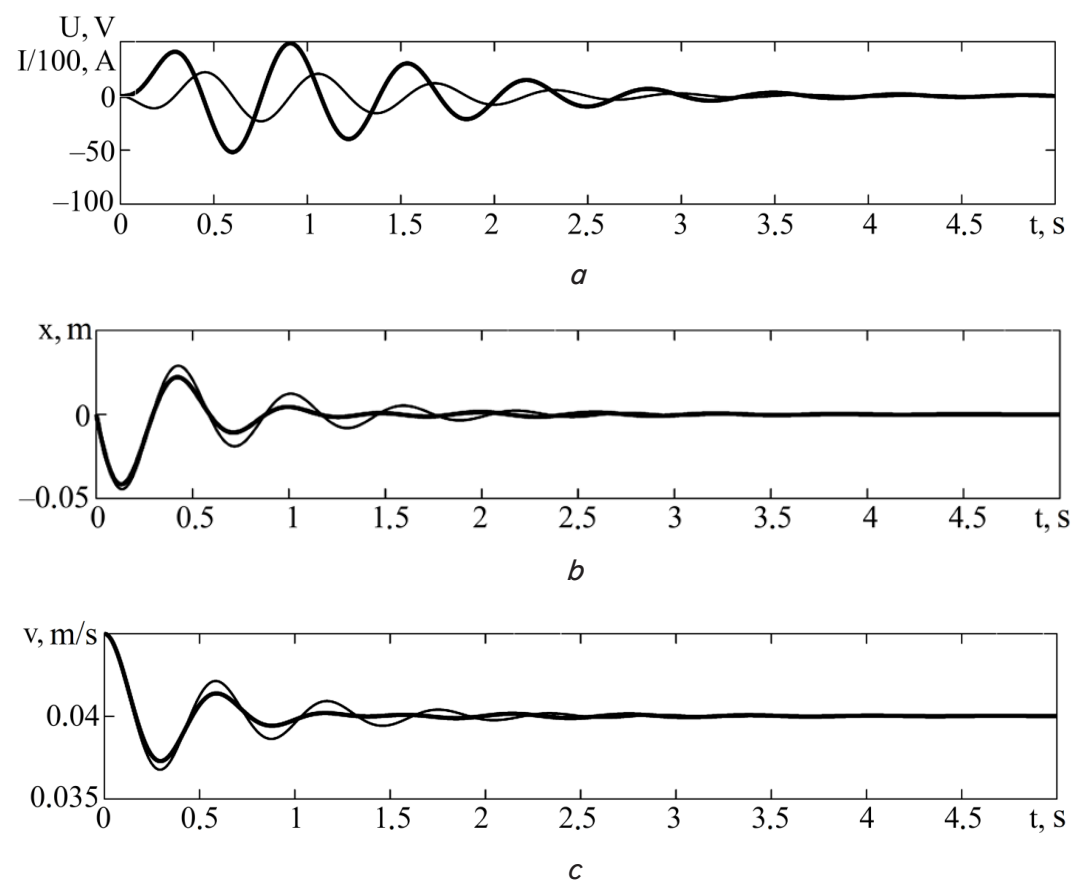

Fig. 9. Results of modeling operating modes of the shock absorber: $a-$ voltage and current of the shock absorber (thin and bold line, respectively);

$b$ - displacement of armature of the shock absorber of basic and developed design (thin and bold line, respectively); $c$ - speed of armature of the shock absorber of basic and developed design (thin and bold line, respectively) 
The analysis of free oscillation simulation reveals that the maximum amplitude is the second one - the second negative value, which is formed at about 0.45 to $0.55 \mathrm{~s}$ from the onset of the process (Fig. 9). This is due to the inductance of the shock absorber winding. As early as at the first oscillation, there is a possibility to damp the oscillations, there is a current and voltage in the winding of the shock absorber.

Based on the simulation results, it was established that the maximum module value of current is $0.234 \mathrm{~A}$, and voltage $52.9 \mathrm{~V}$. It takes about $3 \mathrm{~s}$ for the process of full damping of oscillations over 4 cycles. Compared with the basic design, the amplitude of armature oscillations and its speed decreased from 13 to $85 \%$ over the first three cycles, indicating the greater efficiency of the electromechanical shock absorber operation compared with the hydraulic one. The recuperated energy amounted to $3.3 \mathrm{~J}$, and the scattered - to $11.5 \mathrm{~J}$.

The originality of the derived mathematical model, first of all, is predetermined by the combination of sufficiently accurate, and accounting for the geometry of a magnetic system, magnetic field calculations using the method of finite elements, with the classical method of solving a Lagrange differential equation for the electromechanical system, which underlies the procedure. Second, special attention must be paid to the originality of the structure of the shock absorber itself, which, in contrast to those considered in the review, has a very simple design (a single permanent magnet), which greatly simplifies the assembly of the shock absorber.

Further advancement of the mathematical model could be taking into consideration losses in the steel of a magnetic conductor in the electric shock absorber by introducing additional equivalent electric circuits.

The mathematical model in the form of a Cauchy problem makes it possible to use it as a component of models of the larger order, for example, a model of the trolley for a subway car, in general. Such models allow the derivation of coefficients for motion smoothness and the dynamics of a subway car.

\section{Conclusions}

1. Based on solving a Lagrange equation for the electromechanical system, we have devised a procedure for modeling the electromechanical shock absorber based on a mathematical model. Model features are the following. The model takes the form of a Cauchy problem, convenient to use when simulating the processes of shock absorber operation. Two generalized coordinates have been selected (the charge and armature displacement). The components of the Lagrange equation have been identified.

2. According to the results of magnetic field calculation, followed by a regression analysis, we have obtained polynomial dependences of flux linkage derivatives for the current and the linear armature displacement, which enable the identification of a generalized mathematical model of the electromechanical shock absorber.

3. Based on the results from free oscillation simulation, it has been established that the maximum module value of current is $0.234 \mathrm{~A}$, and voltage $-52.9 \mathrm{~V}$. It takes about $3 \mathrm{~s}$ for the process of full damping of oscillations over 4 cycles. Compared with the basic design, the amplitude of armature stroke oscillations and its speed decreased from 13 to $85 \%$ over the first three cycles, indicating the greater efficiency of the electromechanical shock absorber operation compared with the hydraulic one. The recuperated energy amounted to $3.3 \mathrm{~J}$, and the scattered energy - $11.5 \mathrm{~J}$.

\section{References}

1. Serdobintsev, E. V., Ye Win Han (2013). Vertical Oscillations of the Metro Wagon with Pneumatic Suspension. Mir transporta, 2, 78-84.

2. Liubarskyi, B., Lukashova, N., Petrenko, O., Pavlenko, T., Iakunin, D., Yatsko, S., Vashchenko, Y. (2019). Devising a procedure to choose optimal parameters for the electromechanical shock absorber for a subway car. Eastern-European Journal of Enterprise Technologies, 4 (5 (100)), 16-25. doi: https://doi.org/10.15587/1729-4061.2019.176304

3. Serdobintsev, E., Zvantsev, P., Ye Win Han (2014). Choice of parameters for a metro coach with pneumatic springs. Mir transporta, 1, $34-41$.

4. Lukashova, N., Pavlenko, T., Liubarskyi, B., Petrenko, O. (2018). Analysis of constructions of resports lingings of rail city electric mobile composition. Systemy upravlinnia, navihatsiyi ta zviazku. Zbirnyk naukovykh prats, 5 (51), 65-68. doi: https:// doi.org/10.26906/sunz.2018.5.065

5. Passazhirskoe vagonostroenie. Katalog. Kryukovskiy vagonostroitel'niy zavod. Available at: http://www.kvsz.com/images/ catalogs/tsn.pdf

6. Kolpakhch'yan, P. G., Shcherbakov, V. G., Kochin, A. E., Shaikhiev, A. R. (2017). Sensorless control of a linear reciprocating switchedreluctance electric machine. Russian Electrical Engineering, 88 (6), 366-371. doi: https://doi.org/10.3103/s1068371217060086

7. Forster, N., Gerlach, A., Leidhold, R., Buryakovskiy, S., Masliy, A., Lyubarskiy, B. G. (2018). Design of a Linear Actuator for Railway Turnouts. IECON 2018 - 44th Annual Conference of the IEEE Industrial Electronics Society. doi: https://doi.org/10.1109/ iecon.2018.8591471

8. Sergienko, A. N. (2013). Matematicheskaya model' kolebaniy v hodovoy sisteme avtomobilya s elektromagnitnym dempfirovaniem. Visnyk Natsionalnoho tekhnichnoho universytetu "KhPI". Ser.: Transportne mashynobuduvannia, 31, 86-93.

9. Gysen, B. L. J., van der Sande, T. P. J., Paulides, J. J. H., Lomonova, E. A. (2011). Efficiency of a Regenerative Direct-Drive Electromagnetic Active Suspension. IEEE Transactions on Vehicular Technology, 60 (4), 1384-1393. doi: https://doi.org/10.1109/ tvt.2011.2131160 
10. Sulym, A. O., Fomin, O. V., Khozia, P. O., Mastepan, A. G. (2018). Theoretical and practical determination of parameters of on-board capacitive energy storage of the rolling stock. Naukovyi Visnyk Natsionalnoho Hirnychoho Universytetu, 5, 79-87. doi: https:// doi.org/10.29202/nvngu/2018-5/8

11. Kolpakhchyan, P. G., Shcherbakov, V. G., Kochin, A. E., Shaikhiev, A. R. (2017). Mathematical simulation and parameter determination of regulation of a linear electrical reciprocating machine. Russian Electrical Engineering, 88 (5), $259-264$. doi: https://doi.org/10.3103/s1068371217050054

12. Kolpakhchyan, P., Zarifian, A., Andruschenko, A. (2017). Systems Approach to the Analysis of Electromechanical Processes in the Asynchronous Traction Drive of an Electric Locomotive. Studies in Systems, Decision and Control, 67-134. doi: https:// doi.org/10.1007/978-3-319-51502-1_3

13. Rymsha, V. V., Radimov, I. N., Gulyy, M. V., Kravchenko, P. A. (2010). An advanced chain-field model of a switched reluctance motor. Elektrotekhnika i Elektromekhanika, 5, 24-26.

14. Buriakovskyi, S., Liubarskyi, B., Maslii, A., Pomazan, D., Panchenko, V., Maslii, A. (2019). Mathematical Modelling of Prospective Transport Systems Electromechanical Energy Transducers on Basis of the Generalized Model. 2019 9th International Conference on Advanced Computer Information Technologies (ACIT). doi: https://doi.org/10.1109/acitt.2019.8779998

15. Meeker, D. (2013). Finite Element Method Magnetics: Magnetics Tutorial. Available at: http://www.femm.info/wiki/ MagneticsTutorial

16. Kolpakhch'yan, P. G., Shcherbakov, V. G., Kochin, A. E., Shaikhiev, A. R. (2017). Sensorless control of a linear reciprocating switchedreluctance electric machine. Russian Electrical Engineering, 88 (6), 366-371. doi: https://doi.org/10.3103/s1068371217060086

17. Riabov, I., Liubarskyi, B. (2018). Determination of Phase Flux-Linkage of Flux Switching Motor with Spatial Magnetic System. 2018 International Conference on Industrial Engineering, Applications and Manufacturing (ICIEAM). doi: https:// doi.org/10.1109/icieam.2018.8728773 